\title{
BMJ Open Protocol of the Swiss Longitudinal Cohort Study (SWICOS) in rural Switzerland
}

Andreas W Schoenenberger, ${ }^{1}$ Franco Muggli, ${ }^{2}$ Gianfranco Parati, ${ }^{3,4}$ Augusto Gallino, ${ }^{5}$ Georg Ehret, ${ }^{6}$ Paolo M Suter, ${ }^{7}$ Renate Schoenenberger-Berzins, ${ }^{8}$ Therese J Resink, ${ }^{9}$ Paul Erne ${ }^{9}$

To cite: Schoenenberger AW, Muggli F, Parati G, et al. Protocol of the Swiss Longitudinal Cohort Study (SWICOS) in rural Switzerland. BMJ Open 2016;6: 013280. doi:10.1136/bmjopen-2016013280

- Prepublication history and additional material is available. To view please visit the journal (http://dx.doi.org/ 10.1136/bmjopen-2016013280).

AWS, FM and PMS contributed equally.

Received 4 July 2016 Revised 30 September 2016 Accepted 12 October 2016

\section{CrossMark}

For numbered affiliations see end of article.

Correspondence to Professor Therese J Resink; therese-j.resink@unibas.ch

\section{ABSTRACT}

Introduction: Increased longevity and consequent major changes in demographics and population lifestyles necessitate new approaches to reduce the burden of ageing-related diseases (including cardiovascular disease) and maintain an optimal quality of life. This study aims to examine and longitudinally follow health status and disease risk factors in a Swiss rural cohort, evaluating all health-related research and practice disciplines to assure development of new implementable and successful preventive strategies for healthy ageing.

Methods and objectives: Small Swiss villages with low migration rates will be selected for this study. 2 villages (Cama/Lostallo) have already been selected as initial study sites. All residents (age $\geq 6$ years, no upper age limit) are eligible. The target enrolment number per village is 300 . Examinations and measurements encompass medical history, anthropometry, cardiac and vascular health, pulmonary function, physical performance, nutritional, mental and emotional status, biochemical and molecular analyses. Follow-up examinations (identical to baseline) will be performed after 5 and 10 years, and in 10-year intervals thereafter. The major objective is to assess, and observe change in, health status over time in a prospective manner. Secondary objectives are to: (1) identify 'hidden' (asymptomatic and/or unrecognised) health problems which enhance risk for chronic diseases; (2) identify barriers to accessing healthcare and adapting health behaviours; (3) evaluate efficacy of present preventive strategies and recommendations; (4) evaluate knowledge and attitude towards ongoing health programmes and public health recommendations; (5) monitor change and progress towards the national health objectives; (6) formulate new preventive strategies and recommendations based on the findings and knowledge base of the past 10 years; (7) formulate models for successful prevention of chronic diseases and for healthy ageing.

Ethics and dissemination: The Ethics Committee of Nordwest-und Zentralschweiz approved this study (EKNZ 2014-209). It is registered at ClinicalTrials.gov (NCT02282748). Findings will be disseminated through scientific articles/presentations and public events.

\section{Strengths and limitations of this study}

- The study is epidemiological in nature and directed towards monitoring of ageing in good health and improving quality of life rather than extending lifespan.

- In addition to documentation of conventional epidemiological parameters of cardiovascular health, it uses contemporary technologies including home blood pressure (BP) monitoring, 24-hour BP recordings, Audicor ECG, TensioMed oscillometric device for BP measurement, central $\mathrm{BP}$ estimate and oscillometric arterial stiffness assessment.

- Establishment of a well-defined database on the health status (including issues of mental and physical fitness) and cardiovascular disease risk factors of a free-living population in Switzerland will create a basis for research in other disciplines such as neuropsychology, gerontology and geriatrics.

- Our approach may aid other countries with comparable modern population and socioeconomic profiles in designing strategies to contemporise data on population health and to improve preventive population-based programmes.

- The voluntary random sampling of the registry might generate a bias, and motivation of the participants to come for follow-up visits cannot be predicted.

\section{INTRODUCTION}

Life expectancy at birth in Switzerland is currently one of the highest in the world, resulting from a significant rise during the 20th century. Between 1900 and today, it has risen from 46.2 to 80.8 for men and from 48.8 to 84.9 for women. ${ }^{1}$ The promotion of healthy, independent and active ageing is a public health priority since longevity is only desirable if accompanied by good health and high quality of life. Ageing is associated with development of several chronic diseases and 
one particular objective in the promotion of healthy ageing in Switzerland is improvement of strategies aimed at primary prevention. ${ }^{2-5}$ Cardiovascular disease (CVD), which is the leading cause of death and serious illness in Switzerland, ${ }^{6}$ has long been the focus of several risk factor identification studies.

In 1948, when little was known about the general causes of heart disease and stroke, the Framingham Heart Study helped to contribute, in a major way, to a better understanding of the principal risk factors for CVD (high blood pressure, high blood cholesterol, smoking, obesity, diabetes and physical inactivity) $)^{7-10}$ and the Framingham Heart Study became one of the most renowned studies in medical history. Other studies followed, such as the Münster Heart Study (PROCAM), initiated in 1979 in Germany. The aim was to examine cardiovascular risk factors and cardiovascular events in 17437 men and 8065 women at work. ${ }^{11}{ }^{12}$ Participants were evaluated at baseline and were followed longitudinally. The PROCAM cardiovascular risk score is currently used by the Swiss Atherosclerosis Association (AGLA), ${ }^{13}$ among many other users. The Baltimore Longitudinal Study of Aging (BLSA) is one of the longest ongoing longitudinal studies of ageing in the world. ${ }^{14}$ The BLSA initially focused on the physical and cognitive changes associated with normal ageing, free of disease and later addressed the inter-relationship between disease and age-related changes, looking at their combined effect on physical and cognitive function. The central BLSA question of 'What is aging?' now extends to exceptional ageing, targeting rare individuals who survive well into their $80 \mathrm{~s}$ with no health problems. There are no equivalent studies devoted to healthy ageing or the degree of ageing in a healthy population in Switzerland.

Switzerland has a particularly high life expectancy and is different from other European countries with regard to fundamental features such as its healthcare system and health habits. ${ }^{15}$ Particular strengths of the healthcare system include guaranteed access to healthcare, the broad spectrum of benefits and services covered by the mandatory health insurance system, interest in prevention and awareness of health value, and the high quality of care provided ${ }^{15}{ }^{16}$ However, weaknesses of the system include poor targeted management, incomplete statistical and analytical bases and inadequate investment in prevention and in early detection of diseases. ${ }^{15}{ }^{16} \mathrm{In}$ Switzerland, a number of population-based cohort studies have been conducted, including a study on peripheral arterial disease in workers of four pharmaceutical companies, ${ }^{17}$ the SAPALDIA study on air pollution and lung disease in adults of eight geographic areas representing the range of environmental, meteorological and sociodemographic conditions of Switzerland, ${ }^{18}$ and studies that focus on epidemiology and genetic determinants of cardiovascular risk factors and diseases in populations living in large cities such as Geneva (the BusSanté study) ${ }^{19}$ and Lausanne (the CoLaus study).$^{20}$ The Swiss Kidney Project on Genes in Hypertension (SKIPOGH), ${ }^{21}$ the Bundesamt für Gesundheit (BAG) Swiss Salt Study ${ }^{22}$ and the BAG Nationales Programm Ernährung und Bewegung (NPEB) $)^{23}$ are recent or ongoing crosssectional studies that address only restricted sets of research questions. SAPALDIA, launched in 1991 as a study to examine effects of air pollution on the respiratory and cardiovascular health in adults (aged 16-60), was recently (2014) converted into a Swiss platform for ageing research, with the intention of expanding the database to include information on outcomes such as multimorbidity, disability and functional decline, frailty, quality of life, as well as health and social service usage, and also to use its biobank of prospectively and longitudinally sampled blood and genetic material to study biological ageing processes. ${ }^{24}$

Cohort studies that follow participants longitudinally are important for many reasons. First, many new diagnostic techniques and therapeutic options have become available and it is important to apply them at the population level, outside of highly selective randomised trials. Second, with increasing longevity and demographic changes in the past decades, the elderly become increasingly important for the implementation of preventive measures. Many pathologies and risk factors have a strong age-related component (eg, dementia, heart failure and hypertension) and will therefore dramatically change in their prevalence and incidence. Consequently, new strategies for prevention and therapy are required. Third, shifts in the risk factor distribution are occurring such as an increase in the prevalence and incidence of overweight and obesity in the younger population strata despite preventive interventions to promote a healthy lifestyle. ${ }^{25}{ }^{26}$ It seems that many of the currently applied recommendations and preventive strategies and approaches to improve the health status in the population are not working and cannot be implemented in a sustainable manner. Fourth, new knowledge on behavioural and neurophysiological risk factors (eg, sleep disorders) as well as aspects of health maintenance are still ignored in daily practice and also in risk factor research at the population level. It is timely to assess these factors outside of laboratory conditions. In view of the epidemiological trends of chronic diseases and the consequent uncontrollable burden on healthcare expenditures, new preventive strategies are urgently required. Fifth, risk for CVD varies between countries and the results of previous studies may therefore apply to the Swiss population only in part. ${ }^{2}$ Sixth, a key concept of this study is to establish a well-defined database on the health status and disease risk factors (Why do certain people get sick and others not?) of a small free-living population in Switzerland which should be the basis for research of other disciplines (for instance, neuropsychology, gerontology, geriatrics). Applied 'health promotion research' can only be made in a setting as suggested in the present study.

Our study therefore aims to create, examine and follow a population-based cohort among inhabitants of 
Switzerland, evaluating in the long term all health-related research and practice disciplines to assure the development of new implementable and successful preventive strategies for healthy ageing. An important benefit of a cohort study over a trial is the ability to study multiple risk factors and disease outcomes simultaneously, thus allowing for the identification of the highest impact preventive strategies. Such a study has a high potential to influence national policies in many aspects of health, health promotion and disease prevention and finally well-being of the population and country.

\section{METHODS AND ANALYSIS}

\section{Study design}

This is a longitudinal prospective cohort study with a population-based cross-sectional baseline examination and long-term longitudinal follow-up.

\section{Study objectives}

The primary objective is to assess the health status, with particular attention to cardiovascular health, and observe the change in health status in a representative sample of the Swiss population over time in a prospective manner.

Secondary objectives are: (1) to identify 'hidden' (asymptomatic and/or unrecognised) health problems (including health behaviours and cognitive factors) which enhance the risk for chronic diseases (eg, CVD, ageing-related diseases, dementia, inter alia); (2) to identify and determine barriers to accessing healthcare and adapting health behaviours; (3) to evaluate the efficacy of the present preventive strategies and recommendations; (4) to evaluate the knowledge and attitude towards ongoing health programmes and public health recommendations; (5) to monitor the change and progress towards the national health objectives; ${ }^{27}$ (6) to formulate new preventive strategies and recommendations based on the findings and the knowledge base of the past 10 years; (7) to formulate and develop models for successful prevention of chronic diseases and for healthy ageing.

Achievement of these objectives should lead to development of a dynamic research team and provide scientific knowledge to be considered in the frame of specific expertise of the participating investigators.

\section{Specific study questions}

The main questions under investigation are:

1. What is the health status and, in particular, the cardiovascular health status of a Swiss population-based cohort and what are typical findings in a Swiss population-based cohort using new diagnostic methods and techniques?

2. What are the dynamics of changes in the health status over time and what are the determinants of and predictors for a negative or positive change in the health status?
3. What are the factors influencing healthy ageing?

4. What are the current national standards (eg, for height, weight, blood pressure, cholesterol levels) and what are the age-related changes of these standards?

\section{Study sites}

Two neighbouring villages in Southern Switzerland, Cama and Lostallo (Canton Graubünden), have been selected as initial study sites based on the following considerations: Swiss population, typical age structure and sex distribution, low migration over time, variety of socioeconomic factors, number of inhabitants sufficient according to sample size calculation, support from local political and medical authorities and favourable infrastructure for this study. It is planned to include further study sites in Switzerland based on the same criteria.

\section{Participants}

Recruitment procedure: First, the municipal authorities and the general practitioners of the selected regions are informed about the project. Second, local nurses and physician assistants, followed by local representatives of the press and media, are contacted and informed. Information flyers are distributed and the study application is made available on the local website. Information sessions for the village population and door-to-door explanatory visits are conducted, and positive feedback of participants is estimated. To correct for volunteer bias, the recruitment is currently based on 'randomised inclusion'. A part of the future participants will first be randomised through a computerised system linked to documents held in the offices of their general practitioner and then invited to participate. The information and education campaign in the first participating village was initiated in October 2014. Recruitment began in March 2015 and will proceed until at least the targeted enrolment number (300) per village is reached.

Eligibility: All residents of the selected villages are eligible and will be invited to participate in the study. As described above, participation is based on voluntary response sampling of the village population.

Inclusion criteria: Age $\geq 6$ years (no upper age limit), for voluntary blood sample age $\geq 18$ years, willingness to participate in long-term study, written informed consent (signed by parents for participants $\geq 6$ and $<14$ years).

Exclusion criteria: There are no exclusion criteria. Pregnancy is not an exclusion criterion for participation in this study. However, if pregnancy is known, the visit is postponed for an examination date after delivery, because important measurements in the context of this study may be biased by pregnancy. In patients with mental illness and unable to provide informed consent, consent is obtained from a proxy.

\section{Examinations and measurements}

All examinations of study participants will be performed at regular time intervals. The investigators perform the 
baseline examinations at designated locations in the specified study sites. The visits, lasting $\sim 90 \mathrm{~min}$, are performed in clinic, and the organisation screens four different individuals per given examination day. After the baseline examination of a study participant, follow-up examinations will be performed after 5, 10 years and in 10-year intervals thereafter. The intervals might vary according to other research questions. The follow-up examinations are identical to the baseline examination. In addition to these examinations, every participant will be contacted annually (by mail or telephone when possible) with a request to complete a short questionnaire (focusing on history, residence and other study issues).

The examination has two major components:

1. Health interview survey using different questionnaires

This component of the study embraces a thorough assessment of the health and disease status of the participants using modern and standardised interview-based techniques (self-administered, partially computerassisted, interviews and structured interviews). The selfadministered health survey questionnaire (in the Italian language) is extensive: to illustrate the nature of the assessment, we present the specific queries pertaining to symptoms, respiratory problems, cardiac problems, general aches and pains, medical history, surgical interventions, and medications as online supplementary information.

2. Clinical and biochemical assessment

This component of the study is complementary to the interview component and involves a series of clinical, biochemical and molecular tests.

Clinical tests encompass anthropometric measurements, evaluation of the cardiovascular system (ie, blood pressure and cardiac function) and lung function, assessment of general cognitive functions, physical performance, nutritional status and emotional status.

Biochemical and molecular tests comprise the following: (1) urine samples: proteinuria, glucosuria, erythrocyturia; (2) blood samples: red and white cell count, sodium, potassium, creatinine, aspartate, transaminase, albumin, lipids, glucose, ferritin, total iron binding capacity, thyroid stimulating hormone; (c) snap-frozen serum samples: systemic genomic, proteomic and metabolomic analyses.

Each participant should fully undergo both examination components (except blood sampling in participants $\geq 6$ and $<18$ years). If the biochemical and/or molecular assessments are refused, the interview survey should be performed whenever possible. Table 1 summarises all examinations and measurements performed in the context of this study.

After the examination, individual counselling is offered to each participant. In participants who wish to receive counselling, the findings of the examination are explained to the participant by one of the investigating physicians and recommendations for prevention are provided. All participants wishing to receive a written report are sent a short summary report of the findings.

\section{Data collection, validation and management}

The physician checks the completeness of selfadministered questionnaires on the arrival of the participant, unclear answers are discussed directly and the physician makes corrections in the presence, and with the consent, of the participant. Results of measurements are documented at the study site on a paper-based questionnaire. After the examination, the questionnaires are collected and subjected to a plausibility check-up by the physician and the study nurse (ie, a four-eye principle). If applicable, questionnaires are formally corrected by the physician with documentation of corrections. The participant's name and address (page 1 of questionnaire) are entered in one electronic database and all other information from the questionnaire is entered in another anonymous electronic database. Both databases may be linked together with the use of a unique identifier allowing identification of the study participant, which is important for the planned cross-sectional follow-up examinations, and the key is kept separately. All data from the questionnaires are entered in the databases using two-pass verification. After data entry, data are checked for completeness and plausibility by the data manager. Incomplete or implausible data are amended by the data manager who is obliged to protocol all changes in the database.

The databases will be encrypted using passwords and stored on one computer. The computer is only accessible with another password. Encrypted backups on two external hard disks are periodically made from both databases. Both hard disks are stored at different locations. As an additional measure against data loss, questionnaires will be stored on paper in a safe place.

Primary data users are those who designed and developed the study and who collected the first cross-sectional data assessment. However, this initial cross-sectional study and data collection will be the basis for a long-term study with different external co-investigators in different biomedical fields. Collaborations with other researchers in the field will be promoted.

\section{Data protection}

In the context of this study, sensitive health data are assessed. Other sensitive data (eg, religious, political, social security or administrative data) are not assessed. Data are handled according to the European Union (EU) Data Protection Directive. ${ }^{28}$

\section{Statistical considerations}

Sample size calculation: To detect a clinically relevant increase in blood pressure from baseline 130 to $135 \mathrm{~mm} \mathrm{Hg}$ at follow-up, 32 participants are needed (assumptions: SD $10 \mathrm{~mm} \mathrm{Hg}$ for blood pressure values, significance level $5 \%$ and power $80 \%$ ). Similarly, to 


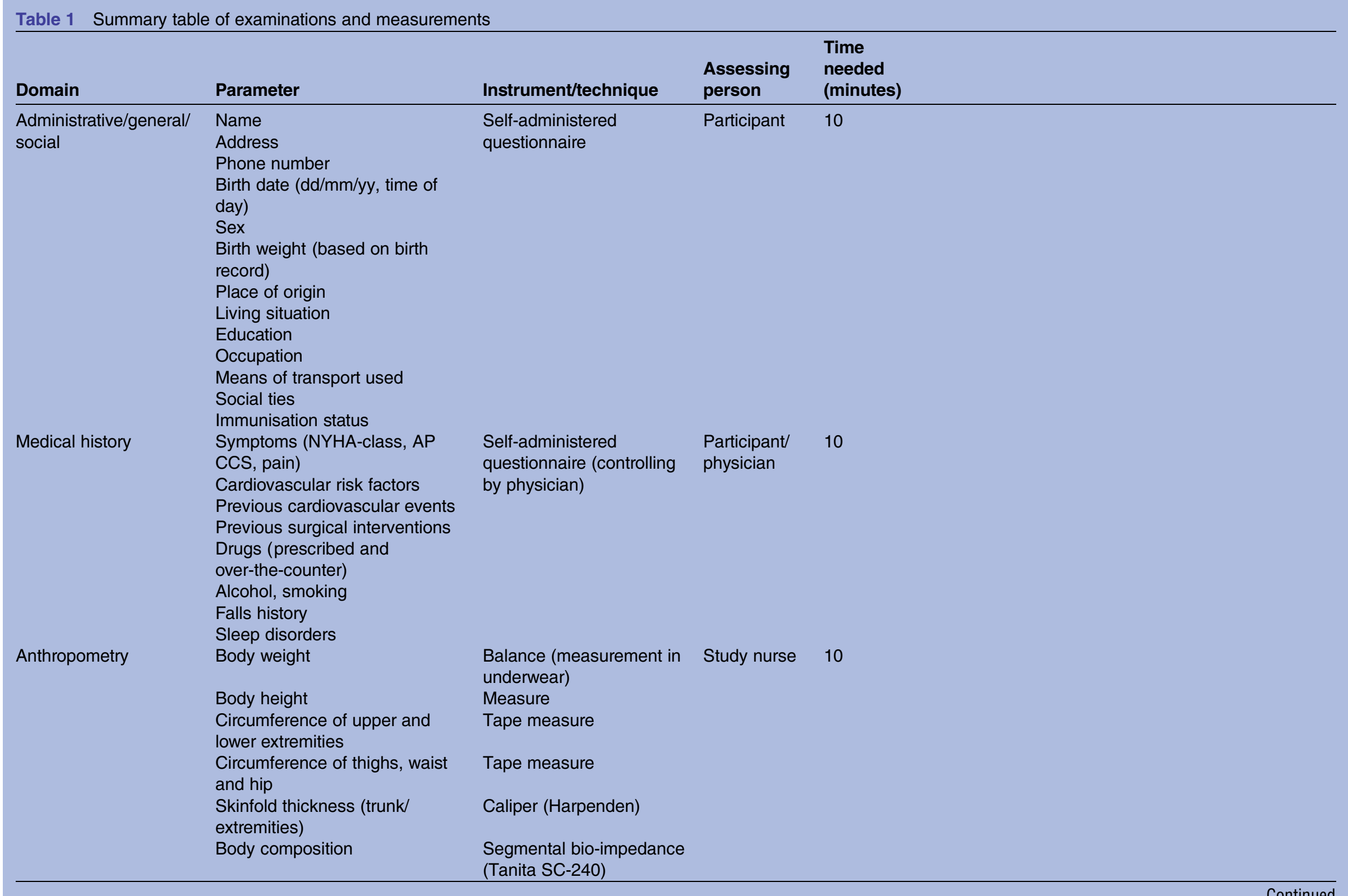




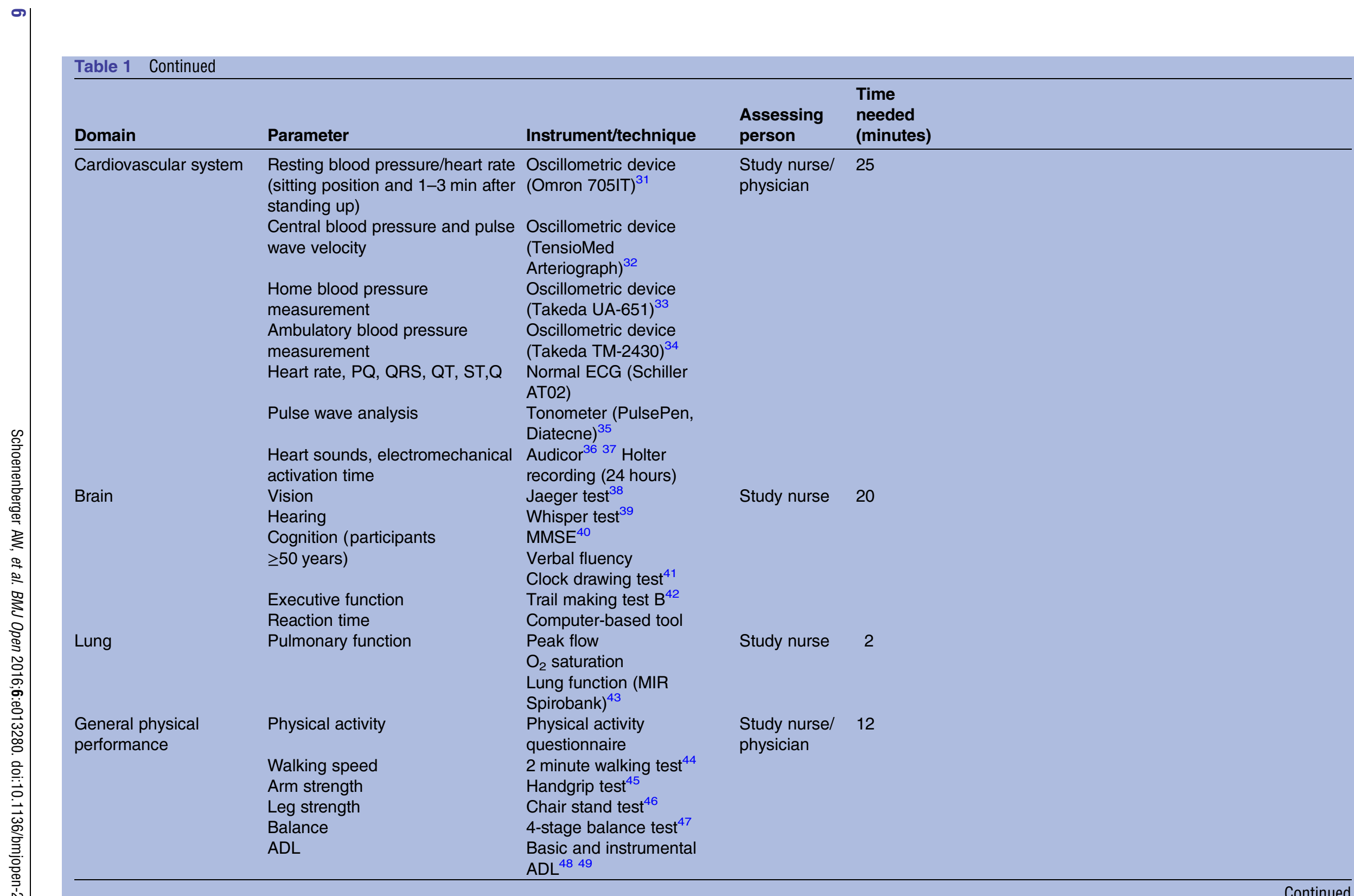
standing up)

Central blood pressure and pulse Oscillometric device

Home blood pressure

Oscillometric device

(Takeda UA-651)

Normal ECG (Schiller

Diatecne $)^{3}$

Heart sounds, electromechanical Audicor ${ }^{36}{ }^{37}$ Holter

activation time recording (24 hours)

Jaeger test ${ }^{38}$

Whisper test ${ }^{39}$

$\mathrm{MMSE}^{40}$

Trail making test $\mathrm{B}^{42}$

er-based tool 


\begin{tabular}{|c|c|c|c|c|c|}
\hline Domain & Parameter & Instrument/technique & $\begin{array}{l}\text { Assessing } \\
\text { person }\end{array}$ & $\begin{array}{l}\text { Time } \\
\text { needed } \\
\text { (minutes) }\end{array}$ & \\
\hline Nutritional status & Weight loss & Self-report question & $\begin{array}{l}\text { Participant/ } \\
\text { physician }\end{array}$ & 3 & \\
\hline Food frequency & Food frequency questionnaire & & & & \\
\hline $\begin{array}{l}\text { Consumer behaviour } \\
\text { and food security }\end{array}$ & $\begin{array}{l}\text { Consumer behaviour/food } \\
\text { security questions }\end{array}$ & & & & \\
\hline \multirow[t]{3}{*}{ Emotional status } & $\begin{array}{l}\text { Depression (participants } \\
\geq 18 \text { years) }\end{array}$ & $\begin{array}{l}\text { Depression screening } \\
\text { questionnaire }{ }^{50}\end{array}$ & Physician & 10 & \\
\hline & Anxiety (participants $\geq 18$ years) & $\begin{array}{l}\text { Anxiety screening } \\
\text { questionnaire }{ }^{50}\end{array}$ & & & \\
\hline & $\begin{array}{l}\text { Self-perceived health } \\
\text { (participants } \geq 18 \text { years) }\end{array}$ & & & & \\
\hline \multirow{7}{*}{$\begin{array}{l}\text { Blood sample (only } \\
\text { participants } \geq 18 \text { years, } \\
\text { voluntary) }\end{array}$} & $\begin{array}{l}\text { Red and white cell count } \\
\text { Sodium, potassium }\end{array}$ & & Study nurse & 5 & \\
\hline & Creatinine & & & & Blood sample in fasting state, measurement in \\
\hline & $\begin{array}{l}\text { Aspartate, transaminase, } \\
\text { albumin }\end{array}$ & & & & validated laboratory \\
\hline & lipids, glucose/HbA1c & & & & \\
\hline & Iron status (ferritin, TIBC) & & & & \\
\hline & TSH & & & & \\
\hline & $\begin{array}{l}\text { Metabolomics, proteomics, } \\
\text { genomics }\end{array}$ & & & & $\begin{array}{l}\text { Blood sample }(50 \mathrm{~mL}) \text { in heparin-free tube, } \\
\text { processed immediately for serum collection, } \\
\text { aliquoting and storage in RNase-free cryotubes in } \\
\text { a sample bank at }-80^{\circ} \text { for later analysis. All } \\
\text { necessary preanalytical precautions will be } \\
\text { implemented. }\end{array}$ \\
\hline \multirow{3}{*}{$\begin{array}{l}\text { Urine sample (only } \\
\text { participants } \geq 18 \text { years, } \\
\text { voluntary) }\end{array}$} & Proteinuria & Urine sample with test strip & Study nurse & 3 & \\
\hline & Glucosuria & & & & \\
\hline & Erythrocyturia & & & & \\
\hline
\end{tabular}


detect a relevant change of 1 Mini Mental State Examination (MMSE) point in the cognitive function between baseline and follow-up, 26 participants are needed (assumptions: SD 1.3 for the difference between baseline and follow-up, ${ }^{17}$ significance level $5 \%$, and power $80 \%$ ). To detect a minimal clinically relevant change in the 2 min gait-speed test, 63 participants are needed (assumptions: SD $20.6 \mathrm{~s}$ for the difference between baseline and follow-up, ${ }^{18}$ significance level 5\%, and power $80 \%$ ). Based on the rule of 10 events per variable in logistic and Cox regression, a predictive model for 10-year mortality involving five predictive variables requires 250 participants under the assumptions of a mortality rate of $2 \%$ per year. ${ }^{29}$ To evaluate the effect of a binary variable with an SD of 0.5 (eg, presence or absence of arterial hypertension) on an outcome (eg, mortality, myocardial infarction) in Cox proportional hazards models, assuming an HR of 0.7 as the effect size, 247 participants are required (further assumptions: significance level $5 \%$ and power $80 \%) .{ }^{30}$ Under the further assumption of a lost to follow-up quote of $10 \%$, it is aimed to recruit $\sim 300$ study participants per village. The recruitment quote is expected to $\sim 50 \%$ of all invited individuals. Each of the selected study sites has a population of at least 600 inhabitants.

Statistical analysis: Statistical analyses will be performed in collaboration with independent Swiss institutions. Analysing institutions will be selected according to the study question under investigation and the collaborating investigators. Statistical methods will be selected according to the study question under investigation. For crosssectional analyses, means or medians will be reported according to the distribution of the continuous variable; proportions will be used for categorical variables. Hypothesis testing will be done using t-test for normally distributed continuous variables and non-parametric tests for non-normally distributed continuous variables; $\chi^{2}$ testing will be used for categorical variables. Linear and/or logistic regression models with or without adjustment for potential confounders will be used whenever appropriate. For the analysis of longitudinal data, survival analysis including Kaplan-Meier curves as well as Cox proportional-hazards models will be used whenever appropriate.

\section{Outcomes}

According to the design and questions of this study, a great variety of outcomes will be analysed. In a first step, data from baseline evaluation will be analysed. The main outcome of this study is the assessment of mortality rate in the follow-up. However, cross-sectional outcomes at baseline and longitudinal outcomes at follow-up will be separately assessed as follows:

1. Cross-sectional outcomes at baseline:

- Prevalence of disorders in the Swiss population (eg, cardiovascular risk factors, orthostatic hypotension, mental and/or emotional disorders, frailty and/or disability, or sleep disorders).
- Ranges of central and 24-hour peripheral blood pressure.

- Associations between different disorders (eg, associations of mental and/or emotional disorders with blood pressure and tonometrically assessed arterial wall properties).

2. Longitudinal outcomes at follow-up:

- Mortality (eg, overall mortality, cardiovascular mortality, cancer mortality).

- Morbidity (eg, non-fatal myocardial infarction, non-fatal stroke, renal failure).

- Functional decline (eg, frailty, disability, cognitive decline, nursing home admission).

\section{Ethical aspects}

Participants will be required to give informed consent for study participation, which includes permission to store a blood sample for future research; to link registries containing data relating to the participant's health (eg, pharmacy, hospital, general practitioner); and finally to link with mortality registries where applicable. The ethical committee and regulatory authorities will receive interim reports and be informed about study stop/end in agreement with local requirements. The study will be carried out in accordance with the protocol and with principles enunciated in the current version of the Declaration of Helsinki, the guidelines of Good Clinical Practice (GCP) issued by the International Conference on Harmonisation of Technical Requirements for Registration of Pharmaceuticals for Human Use (ICH), the Swiss Law and Swiss regulatory authority's requirements.

\section{Dissemination}

The findings of the study will be disseminated through peer-reviewed journals, national and international conference presentations and public events involving the local administrations of the villages where the study participants are resident. Furthermore, data will be presented to Swiss policymakers and healthcare workers to improve preventive strategies to combat CVD and to promote healthy ageing.

Author affiliations

${ }^{1}$ Department of Geriatrics, Inselspital, Bern University Hospital, and University of Bern, Bern, Switzerland

${ }^{2}$ Outpatient's Medical Clinic, Via i Platani, Vezia (Lugano), Switzerland

${ }^{3}$ Department of Cardiology, San Luca Hospital, Istituto Auxologico Italiano,

Milan, Italy

${ }^{4}$ Department of Medicine and Surgery, University of Milano-Bicocca, Milan, Italy

${ }^{5}$ Department of Internal Medicine, Hospital San Giovanni, Bellinzona, Switzerland

${ }^{6}$ Division of Cardiology, University of Geneva, Geneva, Switzerland

${ }^{7}$ Department of Medicine, Outpatient Clinic, University Hospital of Zürich, Zürich, Switzerland

${ }^{8}$ Department of Cardiology, Inselspital, Bern University Hospital, Bern, Switzerland

${ }^{9}$ Laboratory of Signal Transduction, Department of Biomedicine, Basel University Hospital and University of Basel, Basel, Switzerland 
Contributors PE initiated the study. The steering committee (FM, AWS, GP, GE, PMS, AG, PE) contributed to the design and development of the study protocol. AWS performed sample size estimates and planned the statistical analysis approaches. AWS and TJR drafted the manuscript. All authors critically read, edited draft versions and approved the final manuscript.

Funding The study is supported by the Stiftung für Herz-und Kreislaufkrankheiten and the Ärztekasse Genossenschaft.

Competing interests FM and PE are advisors to TensioMed GmbH (Switzerland). PE served as advisor to Inovise Medical (USA), the manufacturer of the Audicor device.

Ethics approval Nordwest-und Zentralschweiz Ethics Committee in Basel (Reference-number EKNZ 2014-209).

Provenance and peer review Not commissioned; externally peer reviewed.

Open Access This is an Open Access article distributed in accordance with the Creative Commons Attribution Non Commercial (CC BY-NC 4.0) license, which permits others to distribute, remix, adapt, build upon this work noncommercially, and license their derivative works on different terms, provided the original work is properly cited and the use is non-commercial. See: http:// creativecommons.org/licenses/by-nc/4.0/

\section{REFERENCES}

1. Swiss Federal Statistical Office: Components of population changeData, indicators_Life expectancy. http://www.bfs.admin.ch/bfs/portal/ en/index/themen/01/06/blank/key/04/04.html

2. Brindle $P$, Beswick A, Fahey $T$, et al. Accuracy and impact of risk assessment in the primary prevention of cardiovascular disease: a systematic review. Heart 2006;92:1752-9.

3. Grundy SM, Balady GJ, Criqui MH, et al. Guide to primary prevention of cardiovascular diseases-a statement for healthcare professionals from the task force on risk reduction. Circulation 1997;95:2329-31.

4. Pearson TA, Blair SN, Daniels SR, et al. AHA guidelines for primary prevention of cardiovascular disease and stroke: 2002 updateconsensus panel guide to comprehensive risk reduction for adult patients without coronary or other atherosclerotic vascular diseases. Circulation 2002;106:388-91.

5. Pearson TA, Palaniappan LP, Artinian NT, et al. American Heart Association Guide for Improving Cardiovascular Health at the Community Level, 2013 update: a scientific statement for public health practitioners, healthcare providers, and health policy makers. Circulation 2013;127:1730-53.

6. Todesursachenstatistik. Sterblichkeit und deren Hauptursachen in der Schweiz. http://www.bfs.admin.ch/bfs/portal/de/index/news/ publikationen.html?publicationID $=5818$

7. D'Agostino RB, Vasan RS, Pencina MJ, et al. General cardiovascular risk profile for use in primary care-the Framingham Heart Study. Circulation 2008;117:743-53.

8. Hubert HB, Feinleib M, Mcnamara PM, et al. Obesity as an independent risk factor for cardiovascular-disease-a 26-year follow-up of participants in the Framingham Heart-Study. Circulation 1983;67:968-77.

9. Kannel WB, Feinleib M, Mcnamara PM, et al. Investigation of coronary heart-disease in families-Framingham offspring study. Am J Epidemiol 1979;110:281-90.

10. Sytkowski PA, Kannel WB, Dagostino RB. Changes in risk-factors and the decline in mortality from cardiovascular-disease. The Framingham Heart-Study. N Engl J Med 1990;322:1635-41.

11. Assmann G, Cullen P, Schulte $H$. The Munster Heart Study (PROCAM). Results of follow-up at 8 years. Eur Heart J 1998;19 (Suppl A):A2-A11

12. Cullen $P$, Schulte $H$, Assmann $G$. The Munster Heart Study (PROCAM): total mortality in middle-aged men is increased at low total and LDL cholesterol concentrations in smokers but not in nonsmokers. Circulation 1997;96:2128-36.

13. Swiss Atherosclerosis Association (Arbeitsgruppe Lipide und Atherosklerose (AGLA) der Schweizerischen Gesellschaft fü Kardiologie). http://www.agla.ch

14. The Baltimore Longitudinal Study of Aging (BLSA). https://www.blsa. nih.gov/about/mission strategy

15. De Pietro C, Camenzind $\mathrm{P}$, Sturny I, et al. Switzerland: health system review. Health Syst Transit 2015;17:1-288.

16. Federal Office of Public Health FOPH: A comprehensive health care strategy. http://www.bag.admin.ch/gesundheit2020/index.html? lang=en
17. Widmer LK, Greenshe A, Kannel WB. Occlusion of peripheral arteries-study of 6400 working subjects. Circulation 1964;30:836-52.

18. Swiss cohort study on air pollution. http://www.sapaldia.ch/en/

19. Guessous I, Bochud M, Theler JM, et al. 1999-2009 Trends in prevalence, unawareness, treatment and control of hypertension in Geneva, Switzerland. PLoS ONE 2012;7:e39877.

20. The CoLaus (Cohorte Lausannoise) study. http://www.colaus.ch/en/ cls home/cls pro home.htm

21. The Swiss Kidney Project on Genes in Hypertension (SKIPOGH). http://www.skipogh.ch/index.php/News

22. Burnier M, Wuerzner G, Bochud M. Salt, blood pressure and cardiovascular risk: what is the most adequate preventive strategy? A Swiss perspective. Front Physiol 2015;6:227.

23. Nationales Programm Ernährung und Bewegung (NPEB). http:// www.bag.admin.ch/themen/ernaehrung_bewegung/13227/

24. SAPALDIA Cohort on Healthy Aging. http://p3.snf.ch/project-148470

25. Ogden CL, Carroll MD, Kit BK, et al. Prevalence of obesity and trends in body mass index among US children and adolescents, 1999-2010. JAMA 2012;307:483-90.

26. Suter PM, Ruckstuhl N. Obesity during growth in Switzerland: role of early socio-cultural factors favouring sedentary activities. Int J Obes 2006;30:S4-S10.

27. Bundesamt für Gesundheit (BAG). Gesundheit2020. Die gesundheitspolitischen Prioritäten des Bundesrates. http://www.bag. admin.ch/gesundheit2020/index.html?lang=de

28. Protection of personal data-European Commission. http://ec europa.eu/justice/data-protection/

29. Vittinghoff $\mathrm{E}, \mathrm{McC}$ Culloch $\mathrm{CE}$. Relaxing the rule of ten events per variable in logistic and Cox regression. Am J Epidemiol 2007;165:710-18.

30. Schoenfeld DA. Sample-size formula for the proportional-hazards regression model. Biometrics 1983;39:499-503.

31. Topouchian J Agnoletti D, Blacher J, et al. Validation of four devices: Omron M6 Comfort, Omron HEM-7420, Withings BP-800, and Polygreen KP-7670 for home blood pressure measurement according to the European Society of Hypertension International Protocol. Vasc Health Risk Manag 2014;10:33-44.

32. Horvath IG, Nemeth A, Lenkey Z, et al. Invasive validation of a new oscillometric device (Arteriograph) for measuring augmentation index, central blood pressure and aortic pulse wave velocity. $J$ Hypertens 2010;28:2068-75.

33. Benetti E, Fania C, Marquez Hernandez V, et al. Validation of the Thermor BIOS BD215 device for home blood pressure measurement according to the European Society of Hypertension International Protocol revision 2010. Blood Press Monit 2014;19:176-9.

34. Yip GW, So HK, Li AM, et al. Validation of A\&D TM-2430 upper-arm blood pressure monitor for ambulatory blood pressure monitoring in children and adolescents, according to the British Hypertension Society protocol. Blood Press Monit 2012;17:76-9.

35. Caravita S, Faini A, Bilo G, et al. Ischemic changes in exercise ECG in a hypertensive subject acutely exposed to high altitude. Possible role of a high-altitude induced imbalance in myocardial oxygen supply-demand. Int J Cardiol 2014;171:e100-2.

36. Erne P. Beyond auscultation-acoustic cardiography in the diagnosis and assessment of cardiac disease. Swiss Med Wkly 2008;138:439-52.

37. Kobza R, Roos M, Toggweiler S, et al. Recorded heart sounds for identification of ventricular tachycardia. Resuscitation 2008;79:265-72.

38. Henkin P, Priest RS, Schiller G. Compendium of ophthalmology. Philadelphia: J.P. Lippincott Company, 1983.

39. Macphee GJ, Crowther JA, McAlpine $\mathrm{CH}$. A simple screening test for hearing impairment in elderly patients. Age Ageing 1988;17:347-51

40. Folstein MF, Folstein SE, McHugh PR. "Mini-mental state." A practical method for grading the cognitive state of patients for the clinician. J Psychiatr Res 1975;12:189-98.

41. Shulman KI, Shedlestky R, Silver I. The challenge of time: clock drawing and cognitive function in the elderly. Int $J$ Geriatr Psychiatry 1986;1:135-40.

42. Tombaugh TN. Trail making test $A$ and $B$ : normative data stratified by age and education. Arch Clin Neuropsychol 2004;19:203-14.

43. Degryse J, Buffels J, Van Dijck Y, et al. Accuracy of office spirometry performed by trained primary-care physicians using the MIR Spirobank hand-held spirometer. Respiration 2012;83:543-52.

44. Rossier P, Wade DT. Validity and reliability comparison of 4 mobility measures in patients presenting with neurologic impairment. Arch Phys Med Rehabil 2001;82:9-13. 
45. Fess EE. Grip strength. In: Casanova JS, ed. Clinical assessment recommendations. Chicago: American Society of Hand Therapists, 1992:41-5.

46. Jones CJ, Rikli RE, Beam WC. A 30-s chair-stand test as a measure of lower body strength in community-residing older adults. Res $Q$ Exerc Sport 1999;70:113-19.

47. Centers for Disease Control and Prevention. http://www.cdc.gov/ steadi/materials.html
48. Katz S, Ford AB, Moskowitz RW, et al. Studies of illness in the aged. The Index of Adl: a standardized measure of biological and psychosocial function. JAMA 1963;185:914-19.

49. Lawton MP, Brody EM. Assessment of older people: self-maintaining and instrumental activities of daily living. Gerontologist 1969;9:179-86.

50. Kroenke K, Spitzer RL, Williams JB, et al. The Patient Health

Questionnaire Somatic, Anxiety, and Depressive Symptom Scales: a systematic review. Gen Hosp Psychiatry 2010;32:345-59. 